\title{
Strong controls of daily minimum temperature on the autumn photosynthetic phenology of subtropical vegetation in China
}

Peixin Ren ${ }^{1}$, Zelin Liu' ${ }^{1}$ Xiaolu Zhou ${ }^{1}$, Changhui Peng ${ }^{1,2}$, Jingfeng Xiao ${ }^{3}$, Songhan Wang ${ }^{4,5}$, Xing Li $i^{3}$ and Peng Li $i^{*}$

\begin{abstract}
Background: Vegetation phenology research has largely focused on temperate deciduous forests, thus limiting our understanding of the response of evergreen vegetation to climate change in tropical and subtropical regions.

Results: Using satellite solar-induced chlorophyll fluorescence (SIF) and MODIS enhanced vegetation index (EVI) data, we applied two methods to evaluate temporal and spatial patterns of the end of the growing season (EGS) in subtropical vegetation in China, and analyze the dependence of EGS on preseason maximum and minimum temperatures as well as cumulative precipitation. Our results indicated that the averaged EGS derived from the SIF and EVI based on the two methods (dynamic threshold method and derivative method) was later than that derived from gross primary productivity (GPP) based on the eddy covariance technique, and the time-lag for $E G S_{\text {sif }}$ and EGS $_{\text {evi }}$ was approximately 2 weeks and 4 weeks, respectively. We found that EGS was positively correlated with preseason minimum temperature and cumulative precipitation (accounting for more than $73 \%$ and $62 \%$ of the study areas, respectively), but negatively correlated with preseason maximum temperature (accounting for more than $59 \%$ of the study areas). In addition, EGS was more sensitive to the changes in the preseason minimum temperature than to other climatic factors, and an increase in the preseason minimum temperature significantly delayed the EGS in evergreen forests, shrub and grassland.
\end{abstract}

Conclusions: Our results indicated that the SIF outperformed traditional vegetation indices in capturing the autumn photosynthetic phenology of evergreen forest in the subtropical region of China. We found that minimum temperature plays a significant role in determining autumn photosynthetic phenology in the study region. These findings contribute to improving our understanding of the response of the EGS to climate change in subtropical vegetation of China, and provide a new perspective for accurately evaluating the role played by evergreen vegetation in the regional carbon budget.

Keywords: Carbon cycle, Evergreen vegetation, Plant phenology, Solar-induced Fluorescence, Climate change, MODIS, Eddy covariance

\footnotetext{
* Correspondence: lipeng_gz@126.com

${ }^{1}$ College of Geographic Science, Hunan Normal University, Changsha 410081,

China

Full list of author information is available at the end of the article
}

(c) The Author(s). 2021 Open Access This article is licensed under a Creative Commons Attribution 4.0 International License, which permits use, sharing, adaptation, distribution and reproduction in any medium or format, as long as you give appropriate credit to the original author(s) and the source, provide a link to the Creative Commons licence, and indicate if changes were made. The images or other third party material in this article are included in the article's Creative Commons licence, unless indicated otherwise in a credit line to the material. If material is not included in the article's Creative Commons licence and your intended use is not permitted by statutory regulation or exceeds the permitted use, you will need to obtain permission directly from the copyright holder. To view a copy of this licence, visit http://creativecommons.org/licenses/by/4.0/. 


\section{Introduction}

Vegetation phenology refers to the rhythm of growth and development in the life cycle of plants, which is closely associated with seasonal changes in the environment (Suepa et al. 2016). The life cycle comprises biological events that occur throughout the year such as budding, flowering, fruiting, defoliation and dormancy during the growth of plants in a year (Helmut 1974; Vrieling et al. 2018). Vegetation phenology is a key indicator of climate change, and it can have a significant impact on the cycles of carbon, water, and energy in terrestrial ecosystems (Xiao et al. 2009; Richardson et al. 2013). Apart from gaining a better understanding of plant responses to climate change, studies on vegetation phenology can help us better understand the mechanisms involved in the exchange of matter and energy between vegetation and the atmosphere, and more accurately evaluate the contribution of vegetation to the global carbon budget (Piao et al. 2008; Penuelas et al. 2009; Richardson et al. 2013).

A large number of studies based on ground observations and satellite remote sensing monitoring have reported an advance in the start of vegetation growing season (SOS) during spring (Menzel et al. 2006; Fu et al. 2015) and a delay in the end of growing season (EGS) in autumn (Liu et al. 2016; Piao et al. 2019). Evidence from multiple studies indicated earlier SOS was significantly related to the increase of preseason temperature (Ge et al. 2015; Xu et al. 2018). Compared with SOS, the EGS also determines the length of the entire growing season and plays an important role in maintaining the global carbon balance (Piao et al. 2008; Garonna et al. 2014). However, the mechanisms underlying the response of EGS to climate change remain unclear (Gallinat et al. 2015; Wu et al. 2018). Though multiple studies tried to investigate the relationships between EGS and climate factors, there is still no consistent conclusion (Yang et al. 2017; Wu et al. 2018). For example, recent studies revealed that increase in daytime maximum temperature and nighttime minimum temperature would cause contrasting effects on drought stress, which result in inconsistent relation between autumn vegetation phenology with preseason maximum temperature and minimum temperature (Wu et al. 2018).

Previous studies on vegetation phenology have focused on the deciduous forest in the middle and high latitudes (Fu et al. 2014; Flynn and Wolkovich 2018), while fewer studies have been conducted in subtropical regions with evergreen vegetation. Remote sensing based indicators have been frequently applied in vegetation phenology monitoring, such as Normalized Difference Vegetation Index (NDVI) and Enhanced Vegetation Index (EVI) (Wen et al. 2017; Yuan et al. 2018). However, these vegetation indices based on "greenness" observations can only reflect the greenness information of vegetation, and represent the "potential photosynthesis" of vegetation (Liu et al. 2018). Subtropical regions mainly consist of evergreen forests and do not show significant seasonal changes with respect to canopy "greenness". Therefore, using vegetation index to understand vegetation phenology and the response mechanism of vegetation phenology to climate change in these forests can cause significant bias (Karkauskaite et al. 2017).

The emergence of solar-induced chlorophyll fluorescence (SIF) in the recent decade provides a new opportunity to monitor vegetation phenology from regional to global scales (Guanter et al. 2014; Yoshida et al. 2015; Sun et al. 2017). SIF is measured as light released during photosynthesis between the wavelengths of $650-800 \mathrm{~nm}$, which can directly reflect the dynamic changes of plant photosynthesis (Frankenberg et al. 2014). Compared to traditional vegetation indices that are significantly affected by atmospheric aerosols, soil, snow, and clouds (Zhang et al. 2003; Balzarolo et al. 2016; Liu et al. 2018), SIF can more directly reflect the dynamic changes that occur during photosynthesis and is less sensitive to the influence of clouds or the atmosphere (Joiner et al. 2014). Therefore, SIF is considered to be a reliable remote sensing-based indicator for monitoring the phenology of tropical or subtropical evergreen vegetation, especially in forests that are in the early stages of environmental stress (Köhler et al. 2018; Zuromski et al. 2018). In addition, SIF was also considered more effective in retrieving vegetation phenology in high productivity areas (Guanter et al. 2014; Yang et al. 2015).

A quarter of the land area in China is covered by subtropical forests, characterized by unique vegetation types, high biodiversity, and remarkable ecological functions. These forests play an important role in maintaining the ecological balance in the region. However, there were still few studies on the phenology of subtropical vegetation, especially in EGS. Therefore, understanding the response of subtropical vegetation to climate change is critical, especially in terms of autumn phenology. In this study, we examined the autumn photosynthetic phenology for five vegetation types in subtropical China, including evergreen coniferous forest (ECF), evergreen broadleaved forest (EBF), deciduous broadleaved forest (DBF), shrub and grassland. The SIF, NIRv (near-infrared reflectance of vegetation) and MODIS EVI remote sensing data from 2000 to 2018 were used to extract the autumn phenology of subtropical vegetation in China. The main objectives of the study were as follows: (1) to examine the spatiotemporal patterns of the EGS in the study region; (2) to compare the results of vegetation photosynthetic phenology based on SIF and vegetation index; (3) to analyze the responses of vegetation autumn phenology in subtropical China to maximum temperature $\left(T_{\max }\right)$, minimum temperature $\left(T_{\mathrm{min}}\right)$ and precipitation and then to explore the underlying mechanisms. 


\section{Materials and methods Datasets \\ Remote sensing data}

The satellite SIF data used in this study is provided by Xiao (2019), which is a global high spatio-temporal resolution $\left(0.05^{\circ}, 8\right.$-day) SIF dataset (namely, GOSIF) based on the OCO-2 (Orbiting Carbon Observatory 2) satellite. GOSIF was developed by a data-driven method which established a predictive SIF model from discrete OCO-2 soundings, MODIS remote sensing data and meteorological reanalysis data ( $\mathrm{Li}$ and Xiao 2019a). It has similar and reasonable seasonal period as the original OCO-2 SIF, but it has higher spatial and temporal resolution, global continuous coverage and longer data record ( $\mathrm{Li}$ and Xiao 2019a). This dataset plays an important role in understanding the long-term trends in global photosynthesis, and which has been widely used to evaluate the inter-annual variation in ecosystem productivity ( $\mathrm{Li}$ and Xiao 2019b; Li and Xiao 2020; Qiu et al. 2020). In calculation, we changed the temporal resolution of SIF data from 8 to 16 days by using the maximum synthesis method. The EVI data used in this study were extracted from NASA Earth Science Data (NASA 2015). For the analysis, we used EVI data (2000-2018) extracted from the MOD13C1 v006 dataset, with a spatial resolution of $0.05^{\circ}$ and 16 days' interval. The NIRv was calculated by the product of normalized vegetation index (NDVI) and near infrared reflectance, with a spatial resolution of 0.05 degree (Wang et al. 2021).

\section{Meteorological data}

Meteorological data were obtained from the National Tibetan Plateau Data Center (2019). The dataset is based on the fusion of remote sensing product, reanalysis data set and field station data and has a temporal resolution of $3 \mathrm{~h}$ and a spatial resolution of $0.1^{\circ}$ (Yang et al. 2010). The dataset provides seven near-surface meteorological elements, including air temperature, surface pressure, specific humidity, wind speed, downward shortwave radiation, downward long-wave radiation and precipitation rate (He et al. 2020). In this study, we used daily precipitation, $T_{\max }$ and $T_{\min }$ data to examine the response of EGS to climate change.

\section{Flux and vegetation data}

In this study, carbon flux data of half hour scale in terrestrial ecosystem were used to evaluate the performance of different remote sensing data for monitoring vegetation phenology. The flux data of the Dinghushan and Qianyanzhou research stations from 2003 to 2010 were obtained from the national flux network of China (ChinaFLUX 2013). Coordinate axis rotation and WPL (WebbPearman-Leuning) correction were used to eliminate the effects of topography, air hydrothermal transmission, and observation height on the observed data. Then, the $\mathrm{CO}_{2}$ flux data were partitioned into gross primary productivity (GPP) and total ecosystem respiration. The vegetation data (spatial resolution, $1 \mathrm{~km}$ ) were obtained from the Joint Research Center of European Commission under the project of Global Land Cover 2000. The final regional vegetation classification data for China were obtained by preprocessing the corresponding data (Xu et al. 2005). We excluded cultivated areas affected by anthropogenic activity. For the final analysis, we selected five vegetation types in the subtropical region of China, including evergreen coniferous forest (ECF), evergreen broadleaved forest (EBF), deciduous broadleaved forest (DBF), shrub and grassland. The distribution of the subtropical region and vegetation type were shown in Fig. 1.

\section{Estimation of EGS}

In order to eliminate the background noise, the Savitzky-Golay filter was applied to smooth the SIF, EVI, NIRv and GPP flux time series data (Zhang et al. 2016). We then used the dynamic threshold method and the derivative method to determine EGS, which indicates autumn vegetation phenology (Liu et al. 2016; Filippa et al. 2016). Compared with the fixed threshold method, the dynamic threshold method is advantageous since it eliminates the influence of background noise by allowing a threshold to be set based on the conditions in the study area (White et al. 2009). The equation of the dynamic threshold method is as follows:

$$
X_{\text {ratio }}=\frac{X_{t}-X_{\min }}{X_{\max }-X_{\min }}
$$

where $X_{t}$ is the value of $X$ at a given time $t$, and $X_{\max }$ and $X_{\min }$ are the maximum and minimum values of $X$ in

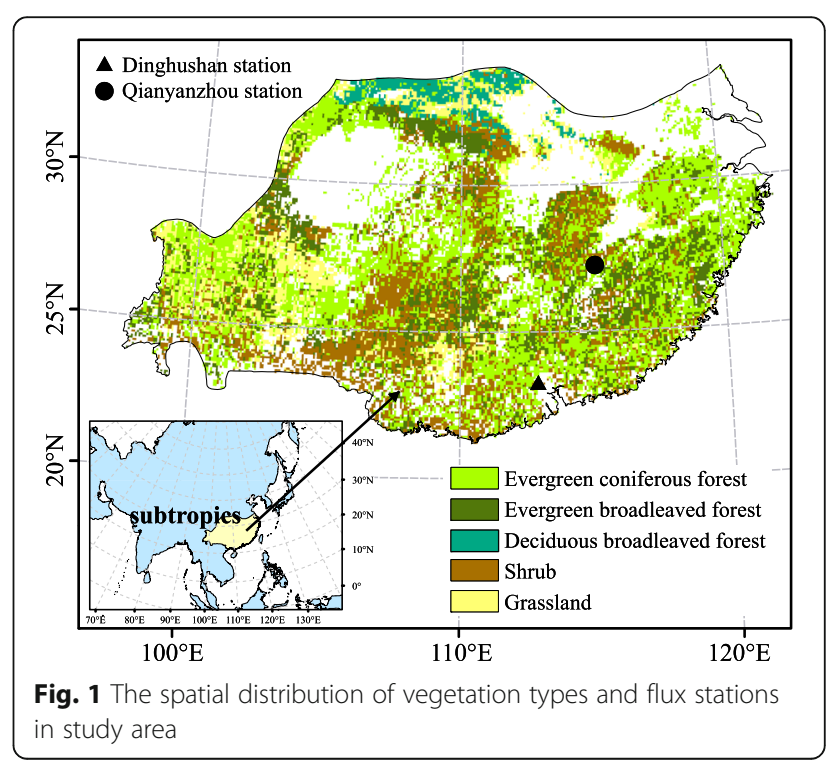


the annual $X$ time series, respectively. $X$ indicates SIF, EVI and NIRv remote sensing data. In this study, the EGS date was defined as the first day of the year in the descending period when the $X_{\text {ratio }}$ reduction value was less than 0.5 as the EGS (Wu et al. 2018).

The derivative method assumes that the EGS is the time point when the $X$ time series decreases rapidly: this corresponds to the points with the minimum slope of the fitting curve (Forkel et al. 2015). Here the $X_{\text {ratio }}$ is calculated as the change in $X$ at time $t$, based on the following equation:

$$
X_{\text {ratio }}=\frac{X_{(t+\Delta t)}-X_{t}}{\Delta t}
$$

where $X_{t}$ represents the value of $X$ corresponding to the time $t . \Delta t$ is value of the time variation. $X$ indicates SIF, EVI and NIRv remote sensing data. In order to make the retrieval phenology more accurate, EGS retrieved from two methods was both used for the analysis.

\section{Analysis}

We first extracted the autumn photosynthetic phenology (i.e., EGS) for each year at each pixel using both derivative and dynamic threshold methods from the GOSIF, NIRv and MODIS EVI datasets for the period from 2000 to 2018. We then calculated the annual average of EGS and analyzed its spatial distribution in the subtropical region. Subsequently, we used flux data to retrieve the annual EGS by the two methods in the study area, in order to evaluate the EGS derived from different remote sensing data. A simple linear regression was used to analyze the spatial distribution and temporal trends of EGS for each pixel from 2000 to 2018. In this analysis, we also compared the trends of the EGS across different vegetation types.

Previous studies showed that precipitation, minimum temperature and maximum temperature all play an important role in regulating vegetation phenology (Piao et al. 2019; Wang et al. 2019b). A partial correlation analysis was used to evaluate the response of the EGS to climatic factors, including precipitation, $T_{\max }$, and $T_{\min }$, during preseason 5 months (with 1 month step). We used the absolute values of the maximum partial correlation coefficients for each pixel to identify the preseason period that was significantly associated with EGS, which was designated as the optimal preseason periods in the study area. Then, we analyzed the relationship between climatic factors and the EGS during the most related preseason periods and determined its significance of each pixel. Using the correlation coefficients, we also assessed the relationship between EGS and climatic factors across different vegetation types.
Finally, to further investigate the response of EGS to climate factors, we conducted multiple regressions to evaluate the sensitivity of EGS to the preseason $T_{\max }$, $T_{\min }$ and cumulative precipitation. The coefficients of each factor in the regression model indicate the sensitivity of EGS to corresponding climatic factors. In this study, we aggregated all data to a $0.1^{\circ} \times 0.1^{\circ}$ grid to match the coarsest resolution among all datasets. In all the calculation and analysis, we excluded the area with low vegetation coverage $(E V I<0.08)$ and retained those areas covering the five types of vegetation in the study.

\section{Results}

Spatial and temporal patterns of EGS in subtropical China There was a distinct latitudinal variation of EGS derived from SIF and EVI data (Fig. 2): an advance of the EGS at higher latitudes and a delay of the EGS at lower latitudes. Furthermore, EGS extracted from SIF data (EGSsif) was earlier than that derived from the EVI data $\left(E G S_{\text {evi }}\right)$. For the two datasets, the spatial distributions of EGS were similar between two methods. In the study area, $\mathrm{EGS}_{\text {sif }}$ extracted by the derivative and dynamic threshold methods were 280.1 and 276 days, respectively, with an average of 278 days (Fig. $2 \mathrm{~b}$ and d). In contrast, EGS $_{\text {evi }}$ of the two methods were 294 and 289.6 days, respectively, with an average of 291.8 days (Fig. 2a and c). In addition, some interesting information was found by comparing EGS estimated by the two types of remote sensing data and flux data from 2003 to 2010 in Fig. 3. At the Qianyanzhou station, the EGS of EVI, SIF and GPP flux data (average of 8 years) by the derivative method were on day 303.9, 291.6 and 278.9, respectively (Fig. 3a). EGS ${ }_{\text {evi }}, E \mathrm{ES}_{\text {sif }}$ and $\mathrm{EGS}_{\mathrm{GPP}}$ estimated by the dynamic threshold method were on day 304.1, 289.6 and 279.5, respectively (Fig. 3b). The average values of EGS retrieved from two kinds of remote sensing data were later than $\mathrm{EGS}_{\mathrm{GPP}}$, and the time-lags were 25 days $\left(E S_{\text {evi }}\right)$ and 11 days $\left(E_{\text {GS }}\right)$, respectively. At the Dinghushan station, $\mathrm{EGS}_{\text {evi, }}, \mathrm{EGS}_{\text {sif }}$ and $\mathrm{EGS}_{\mathrm{GPP}}$ by the derivative method were on day 300.4, 288 and 273.9, respectively (Fig. 3c). For the dynamic threshold method, $E S_{\text {evi }}, E S_{\text {sif }}$ and $E_{G S}$ GPP were on day 299.9, 287.1 and 272.7, respectively (Fig. $3 \mathrm{~d}$ ). The average of $\mathrm{EGS}_{\mathrm{GPP}}$ was 27 days $\left(\mathrm{EGS}_{\text {evi }}\right)$ and 14 days $\left(\mathrm{EGS}_{\text {sif }}\right)$ ahead of the two remote sensing data. Compared with SIF and EVI, EGS retrieved by the NIRv was later for the two methods (Supplementary Material: Figs. S1 and S2).

Across the study area, the trends in the EGS extracted from the SIF and EVI by the two methods were similar (Fig. 4). In terms of spatial distribution, the delays in $\mathrm{EGS}_{\text {evi }}$ and $\mathrm{EGS}_{\text {sif }}$ were restricted to the central part of the study area (Fig. 4). For the derivative method, the delay of $\mathrm{EGS}_{\text {evi }}$ and $\mathrm{EGS}_{\text {sif }}$ was observed in more than $60 \%$ of the total study area, of which $\sim 20 \%$ showed 

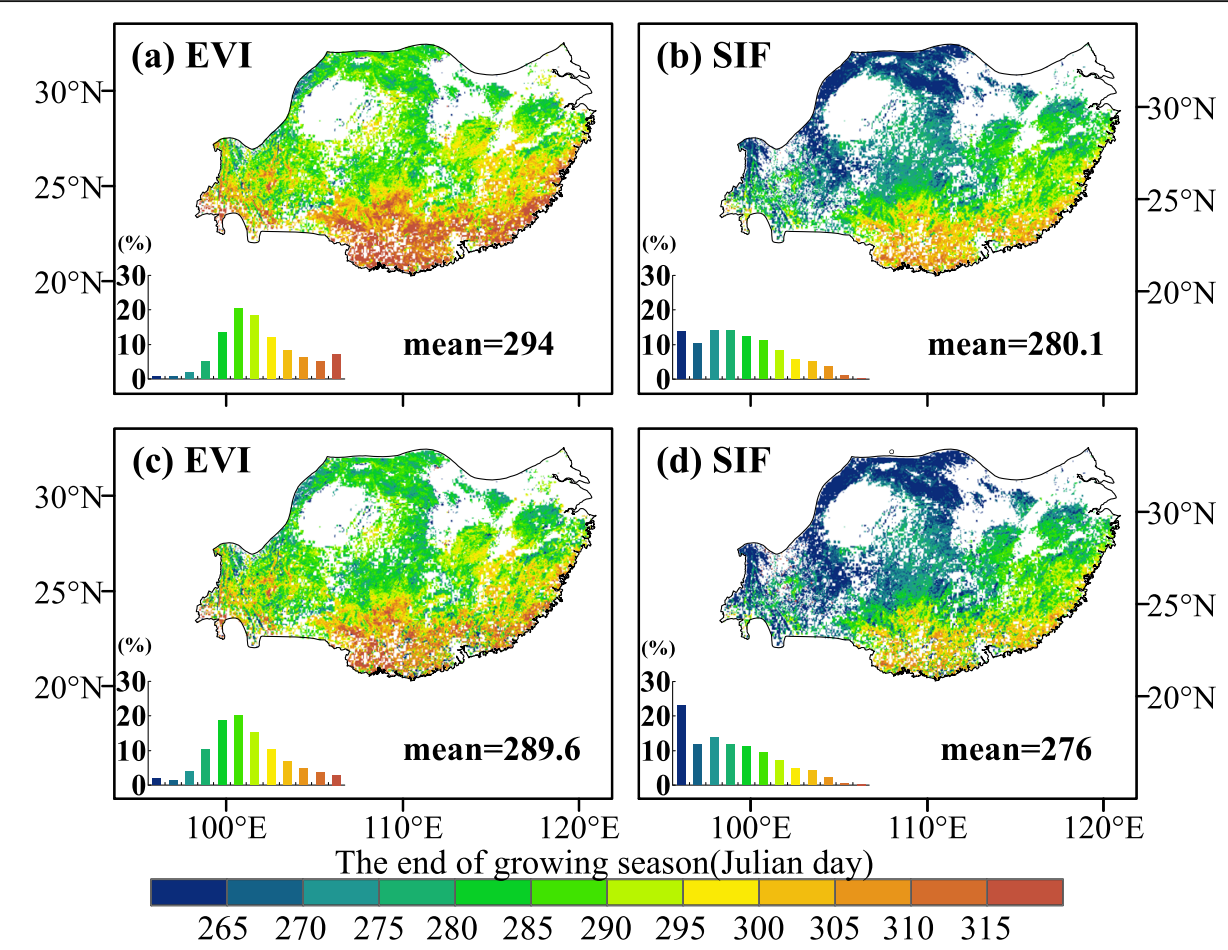

Fig. 2 The spatial patterns of the end of growing season (EGS) in subtropical vegetation in China from 2000 to 2018: MODIS EVI dataset and SIF dataset. $\mathbf{a}-\mathbf{b}$, derivative method and $\mathbf{c}-\mathbf{d}$, dynamic threshold method. Inset plots (the bottom-left of each figure) display the frequency distribution of EGS

significant delays $(P<0.05)$ (Fig. 4a and b). A delay of $\mathrm{EGS}_{\text {evi }}$ and $\mathrm{EGS}_{\text {sif }}$ extracted by the dynamic threshold method was observed in more than $55 \%$ of the total study area, and the pixels with significant delay $(P<$ 0.05 ) for $\mathrm{EGS}_{\text {evi }}$ and $\mathrm{EGS}_{\text {sif }}$ accounted for $13.23 \%$, and $17.77 \%$ of all the pixels in the study region, respectively (Fig. 4c, d). Both EGS evi $_{\text {and }} \mathrm{EGS}_{\text {sif }}$ extracted by the two methods exhibited similar trends across different vegetation types. A delayed EGS was observed across most vegetation types (e.g., evergreen forest, shrub, and grassland), except for the deciduous broadleaved forest (Fig. S3). In contrast, the averaged EGS of DBF retrieved from the two methods showed an advancing trend by 0.09 day.yr ${ }^{-1}\left(\mathrm{EGS}_{\text {evi }}\right)$ or 0.37 day $\cdot \mathrm{yr}^{-1}\left(\mathrm{EGS}_{\text {sif }}\right)$. In addition, in the study area and different vegetation types, the trend in the EGS extracted from the NIRv was different from that of the SIF and EVI (Figs. S4, S5).

\section{Response of EGS to climate drivers}

Based on the above analysis, the SIF showed a better performance than EVI and NIRv in capturing the EGS, and thus we chose EGS sif $_{\text {to }}$ explore the relationship between autumn phenology and climate factors in the study area. At the regional scale, for both two methods, EGS $_{\text {sif }}$ in subtropical China was correlated with $T_{\min }$ during the period of 2-4 months prior to $\mathrm{EGS}_{\text {sif }}$, the median and mean of the period related to $T_{\min }$ were in the
3 months prior to $\mathrm{EGS}_{\text {sif. }}$ The mean of the period related to $T_{\max }$ was in the 2 months to $\mathrm{EGS}_{\text {sif }}$. For the cumulative precipitation, the $\mathrm{EGS}_{\text {sif }}$ was most correlated with the period about 3 months prior to $\mathrm{EGS}_{\text {sif }}$ (Fig. S6).

Based on the partial correlation analysis, we found that a large proportion of the pixels showed positive correlations between $\mathrm{EGS}_{\text {sif }}$ extracted by the two methods and $T_{\min }$ as well as cumulative precipitation (Fig. 5). For the derivative and dynamic threshold methods, about $77.1 \%$ and $73.58 \%$ of the pixels covering the study area showed a positive partial correlation with $T_{\min }$, of which $17.61 \%$ and $16.63 \%$ showed statistically significant relationships $(P<0.05)$, respectively. Similarly, on average, $62.91 \%$ of the pixels covering the study area of the two methods showed a positive partial correlation with preseason cumulative precipitation, and this correlation was significant over $9.5 \%$ of pixels $(P<0.05)$. Compared with the preseason $T_{\min }$ and cumulative precipitation, there were more pixels with negative correlation between the preseason $T_{\max }$ and $\mathrm{EGS}_{\text {sif }}$, accounting for $59.96 \%$ and $59.36 \%$ of the study area for the two methods, respectively (Fig. 5).

The responses of EGS of different vegetation types to climate factors were different (Fig. 6). For two methods, there was a positive partial correlation between EGS and $T_{\min }$ across different vegetation types $\left(R_{\mathrm{P}}>0.51, P<\right.$ 0.05 ; Fig. 6), with the exception of deciduous 


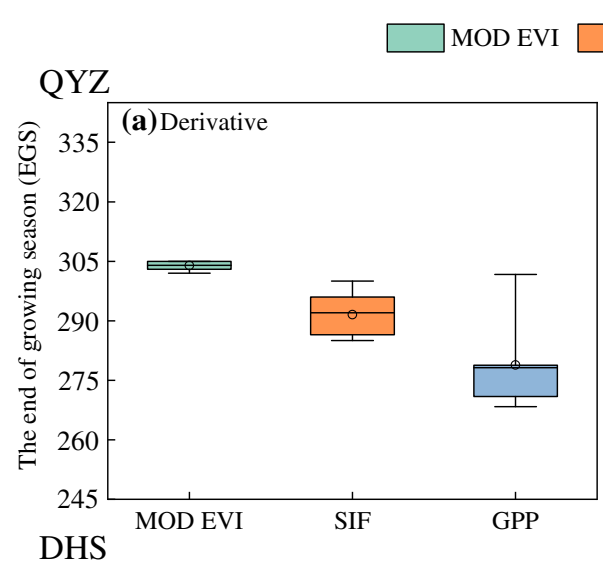

$\square$ SIF $\square$ GPP
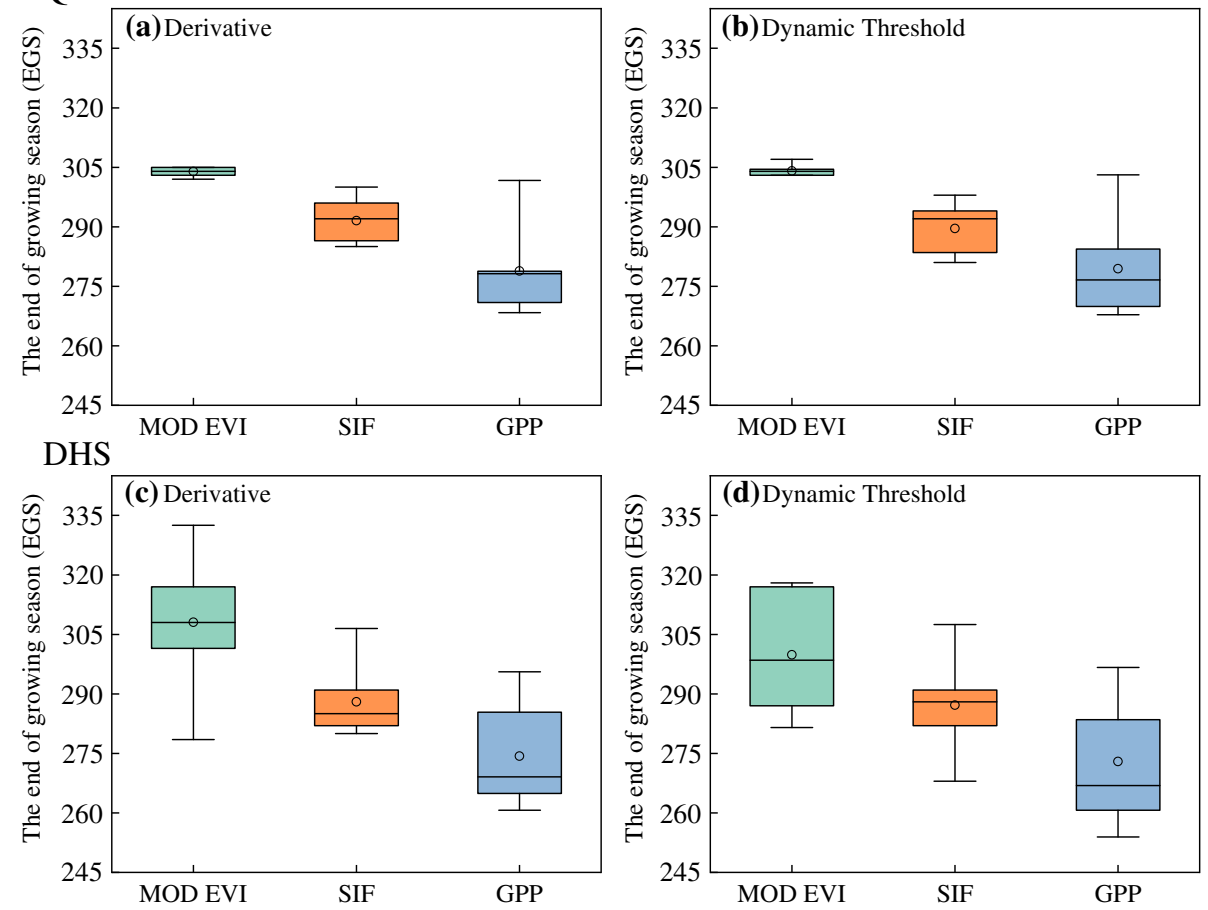

Fig. 3 Comparison of the end of growing season (EGS) retrieved from remote sensing data and flux data. Two ecological monitoring stations were listed, including Qianyanzhou station (QYZ) and Dinghushan station (DHS). Both methods were listed, including derivative and dynamic threshold methods

broadleaved forest $\left(R_{\mathrm{P}}<-0.32, P>0.05\right)$. Preseason cumulative precipitation was positively correlated with $\mathrm{EGS}_{\text {sif }}$ for all vegetation types, and the strongest relationship was observed in the shrub $\left(R_{\mathrm{P}}>0.56, P<0.05\right)$. In contrast, $T_{\max }$ was negatively correlated with $\mathrm{EGS}_{\text {sif }}$ across all vegetation types, except for DBF. Overall, EGS $_{\text {sif }}$ was more strongly correlated with preseason $T_{\text {min }}$ and cumulative precipitation than with preseason $T_{\max }$ (Fig. 6). To further test the results of the partial correlation analysis, we also analyzed the sensitivity of $\mathrm{EGS}_{\text {sif }}$ to climate factors. Both methods showed similar results. The sensitivity of EGS to the preseason $T_{\min }$ was the strongest across all vegetation types $\left(>1.93\right.$ day.sd $\left.{ }^{-1}\right)$, except for DBF (Fig. S7). Conversely, the sensitivity of EGS to the preseason $T_{\max }$ was the weakest across different vegetation types (Fig. S7).

\section{Discussion}

\section{Comparison of satellite-retrieved EGS based on SIF and EVI data}

By comparing SIF with GPP estimated across two flux tower sites in the study area, the SIF dataset used in this study exhibited strong seasonal and interannual dynamics that were consistent with those of daily GPP (Fig. S8), and thus the reconstructed SIF product has a great potential for monitoring the photosynthetic phonology in the study area. We also found that the SIF clearly had an advanced EGS than did EVI, and it was closer to GPP-derived EGS at the two evergreen forest sites. The differences in the seasonal cycle of EVI and SIF could be explained by the differences in the information contained in the two kinds of data resource. On the one hand, the SIF is deemed to be directly linked to photosynthetic activity, which contains major information on photosynthetically active radiation (Walther et al. 2016). While the EVI is more of an approximation for fraction of photosynthetically active radiation, which indicates the photosynthetic potential of the terrestrial vegetation cover (Jiang et al. 2008). Because of the intrinsic limitations of the photosynthetic machinery and external stress factors, the absorbed photosynthetically active radiation by vegetation cannot be completely used for carbon fixation (Baker 2008). In contrast, SIF contains information on not only absorbed photosynthetically active radiation but also environmental stresses that determine photosynthetic light use efficiency (Yoshida et al. 2015; Li and Xiao 2020). Therefore, SIF can be used to track changes in physiological changes induced by environmental stresses in the absence of changes in greenness or structure. This may explain why EGS based on SIF 

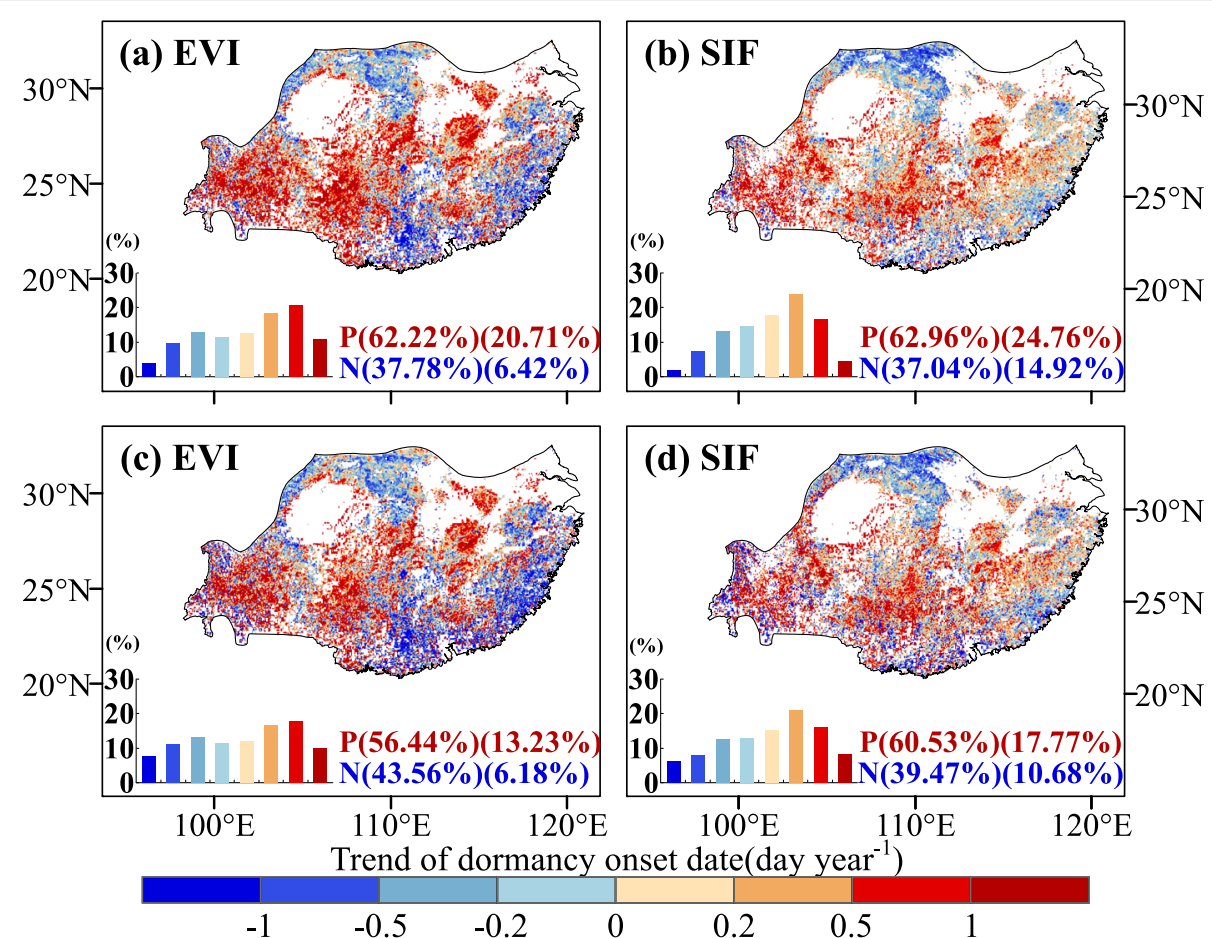

Fig. 4 The spatial patterns of the linear trend of the end of growing season (EGS) of subtropical vegetation in China from 2000 to 2018: MODIS EVI dataset and SIF dataset. $\mathbf{a}-\mathbf{b}$, derivative method and $\mathbf{c}-\mathbf{d}$, dynamic threshold method. A negative value indicates an advance, and a positive value indicates a delay. Inset plots (the bottom-left of each figure) display the frequency distribution of change trend. The proportions of positive $(\mathrm{P})$ and negative $(\mathrm{N})$ (proportions of significant in parentheses) trends are provided

occurred earlier than that based on the "greenness" phenology reflected in EVI data.

On the other hand, SIF is an energy flux emitted from plant chlorophyll molecules a few nanoseconds after light absorption by vegetation (Baker 2008), whereas the EVI was calculated based on vegetation canopy reflectance. Multiple studies have reported that physiological vegetation indices (e.g., chlorophyll) performance better than structural vegetation indices for detecting the autumn photosynthetic phenology for evergreen forests (Wong et al. 2019; Yin et al. 2020). The structural recession of evergreen forest in autumn is gradual, and the photosynthetic rate is mainly controlled by physiology (Gallinat et al. 2015). Our result indicated that autumn photosynthesis in subtropical China forests is mainly stressed by minimum temperature variability, which causes photosynthesis to end before structural recession (Jeong et al. 2017). Therefore, SIF outperformed EVI in detecting the photosynthetic phenology. In addition, although EVI is an advanced vegetation index, it is still affected by clouds and other atmospheric noise (Miura et al. 2001; Huete et al. 2002). In contrast, the SIF is not sensitive to the influence of cloud and atmosphere (Joiner et al. 2014). This may also contribute to the difference in phenology monitoring for SIF and EVI in our study.
Response of vegetation phenology to climate drivers

Different from the earlier spring phenology which was mainly caused by global warming, there is no consistent conclusion on the change trend of EGS and its influencing factors. Therefore, it is difficult to explain the response mechanism of EGS to climate change. Especially for the photosynthesis phenology in the subtropical China, the climate response mechanism of autumn photosynthesis is largely unknown due to the limitation of monitoring methods. Our results indicated that the EGS in subtropical China was slightly delayed, and the change trend of EGS was biome dependent. In temperate regions, multiple studies have also confirmed that the EGS has reported a small delay in recent years; however, there were no widespread delaying trends in autumn phenology (Wang et al. 2019a). Our findings indicated that global climate change can extend the growing season in subtropical vegetation, which can in turn enhance the carbon sink capacity of subtropical vegetation.

Previous studies have shown that temperature plays a key role in regulating vegetation autumn phenology (Cleland et al. 2007; Chuine et al. 2010). For example, the increase of $T_{\max }$ can advance or delay autumn phenology, while the increase of $T_{\text {min }}$ had the opposite effect (Wu et al. 2018). Our results indicated that the increase 


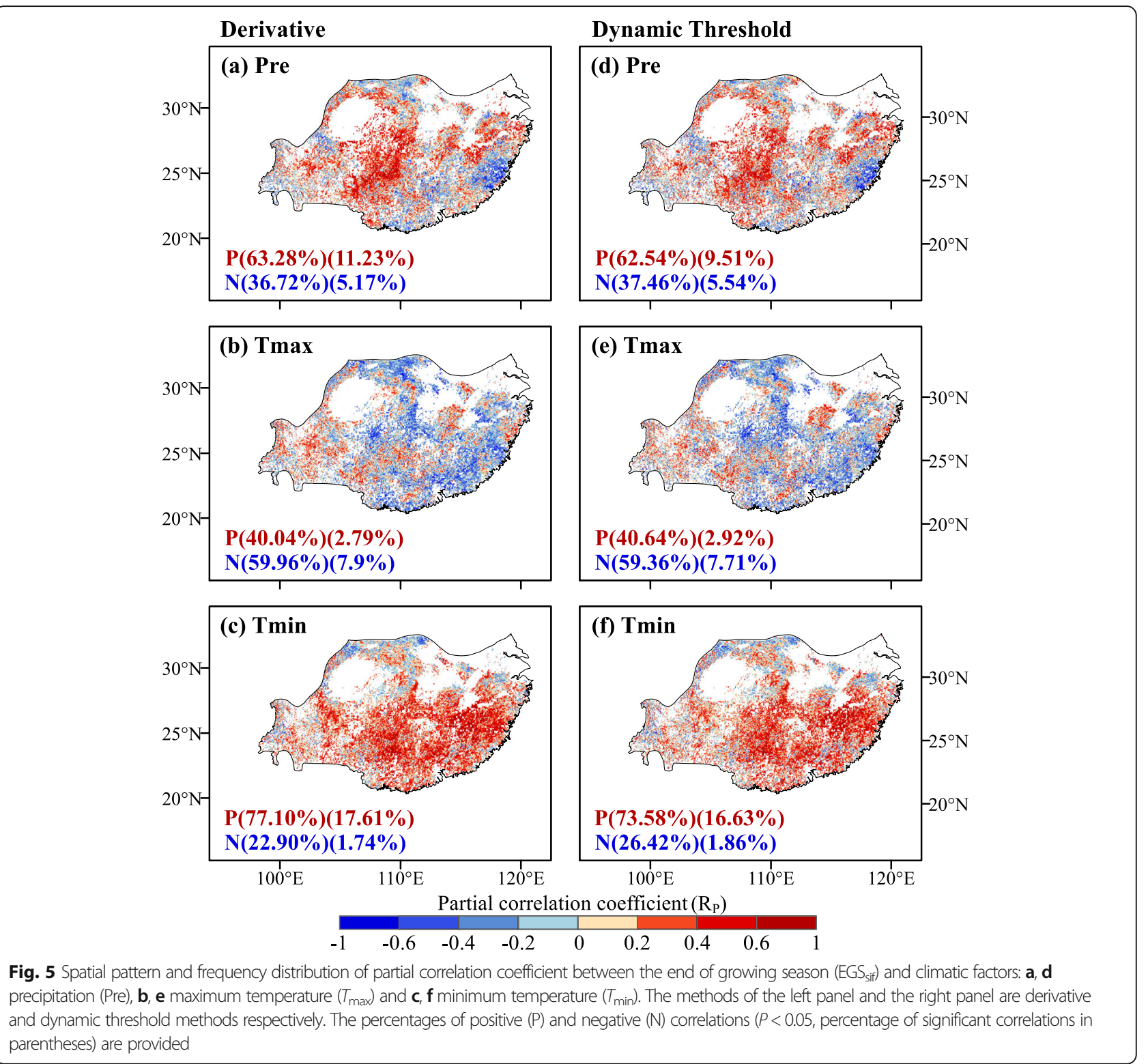

of preseason $T_{\min }$ significantly delayed autumn photosynthetic phenology, extending the growing season in subtropical vegetation in China. The increase of the preseason $T_{\min }$ may delay the coloring of leaves in autumn and reduce the chilling injury caused by low nighttime temperature (Yang et al. 2017). Additionally, the increase of $T_{\min }$ can result in warmer autumn weather, fewer frost days and a delay in the first frost (Liu et al. 2016). In our study, the sensitivity of each vegetation type to the preseason $T_{\min }$ was stronger. This could be due to the fact that subtropical regions are warm and humid, and the nighttime temperature is a limiting factor for vegetation growth, thereby leading to a greater impact on vegetation growth and development than daytime temperature and precipitation. On the other hand, the increase of the preseason $T_{\max }$ led to an earlier EGS and shortened the growing season in our study. The higher subtropical daytime temperature can decrease photosynthetic enzyme activity (Rossi et al. 2017), which can in turn inhibit photosynthesis and shorten the growing season. In addition, the increase of daytime temperature can also lead to higher evapotranspiration and lower soil water use efficiency, resulting in earlier senescence of vegetation (Estiarte and Penuelas 2015; Wu et al. 2018).

Our results also indicated that preseason cumulative precipitation had a positive impact on the EGS, resulting in a longer growing season. Water is one of the important components of protoplasm, and the amount of water in vegetation affects its metabolic intensity and photosynthetic rate (Quetin and Swann 2017). The sensitivity 


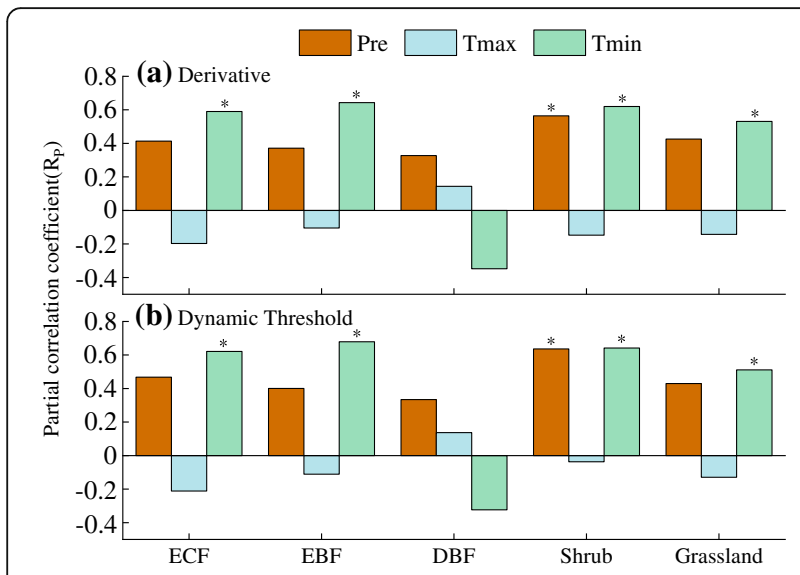

Fig. 6 Correlation between the end of growing season (EGS $S_{\text {sif }}$ ) of different vegetation and climatic factors. Five main vegetation types in this study area were listed, such as evergreen coniferous forest (ECF), evergreen broadleaved forest (EBF), deciduous broadleaved forest (DBF), shrub, and grassland. a derivative method and $\mathbf{b}$ dynamic threshold method. * indicates statistically significant trends at the 95\% $(P<0.05)$ level

of vegetation to water varied with stage of growth (Quetin and Swann 2017). In the subtropical region, the increase of cumulative precipitation will strengthen the absorption of nutrients by vegetation and promote the effective photosynthesis (Bertani et al. 2017), delaying the EGS. Additionally, the impact of precipitation on vegetation phenology in the subtropical region has regional and biological specificity (Zhou et al. 2018). Although there is abundant precipitation in the subtropical region of China, the evergreen forests are more suitable in wet areas. Therefore, the increase of preseason precipitation can enhance the physiological activity of vegetation and photosynthesis, thus delaying the vegetation autumn phenology.

It should be noted that the preseason $T_{\max }$ and $T_{\min }$ had opposite effects on EGS in deciduous broadleaved forests in the study area. Wu et al. (2018) also reported that the $T_{\max }$ and $T_{\min }$ may have the opposite effects on vegetation autumn phenology in different regions. The elevated $T_{\min }$ can increase nighttime respiration and consumption of organic compounds, leading to a shorter growing season; in contrast, higher $T_{\max }$ promotes photosynthesis and delays the EGS (Wu et al. 2018). We speculated that the increase of the maximum temperature delayed the EGS, which may be related to the higher latitude position of deciduous broadleaved forest. In this region, the temperature is relatively low, and the increase of the maximum temperature is beneficial for photosynthesis. Our results also indicated that the effect of minimum temperature on EGS was stronger than that of maximum temperature, which may provide an explanation for the advancing trend of EGS in deciduous broadleaved forest. Another possible explanation is that there had been a slight decrease in rainfall across the deciduous broadleaved forest region over the past two decades (Table S1), which may inhibit the extension of the vegetation growing season. Therefore, the comprehensive effect of climate factors on EGS could partly explain the advancing trend in EGS for deciduous broadleaved forest.

\section{Implications}

Using remote sensing data to retrieve the phenological information of deciduous forest has been well reported (Yang et al. 2015; Liu et al. 2016), while the research on phenological monitoring of evergreen forest was still scarce. Our findings indicated that the remote sensing phenological monitoring based on SIF was closer to the photosynthetic phenology in subtropical vegetation. Our results confirmed a lag between the autumn decrease of photosynthesis and the change in greenness in evergreen forests (Walther et al. 2016). This implies that estimates of the EGS purely based on greenness indices will be biased in evergreen forest in subtropical regions, which translates into errors in the autumn carbon budget. Therefore, compared with traditional vegetation indices, SIF can better capture the autumn decrease stage of photosynthesis of subtropical vegetation and effectively improve the dynamic monitoring of photosynthetic activity in evergreen ecosystems of subtropical regions. Our results provide a new reference for the study of subtropical vegetation phenology, and demonstrate the potential of SIF for simulating carbon budget in evergreen ecosystems of subtropical regions.

In the context of global climate change, it needs to be explained, that how vegetation phenology responds to climate change. However, the response mechanisms of autumn phenology of subtropical vegetation to climate change remain unclear. Our results indicated that the effects of precipitation, maximum and minimum temperature on autumn phenology of subtropical vegetation were discrepant, and elucidating this inconsistency is beneficial to the establishment of subtropical vegetation phenology models. Furthermore, our results suggested the most significant effect of the minimum temperature on autumn phenology of subtropical vegetation, which can improve the understanding of the control factors of subtropical vegetation phenology. Based on our study, we proposed to further explore the effects of climate change on autumn phenology of evergreen forests in other regions of the world. This is an important implication for the improvement of phenological parameterization of terrestrial ecosystem models.

\section{Conclusions}

In this study, we used SIF and EVI data to examine the spatial and temporal variation of autumn vegetation phenology and to analyze its response to climatic factors in subtropical vegetation in China. We found that the 
delay of EGS occurred in evergreen forests, shrub and grassland, but not in the deciduous broadleaved forest. We found that the preseason $T_{\min }$ and cumulative precipitation were positively associated with the delay of EGS (with positive correlation for more than $73 \%$ and $62 \%$ of the study areas for the two methods, respectively). Conversely, the preseason $T_{\max }$ was negatively associated with the EGS (with negative correlation for more than $59 \%$ of the study areas for both methods). In all vegetation types except deciduous broadleaved forest, the increase of $T_{\min }$ also caused the delay of EGS (> 1.93 day.sd $\mathrm{sd}^{-1}$ ), while the increase of preseason $T_{\max }$ advanced it. For precipitation, the increase of cumulative precipitation could delay the EGS across all vegetation types. Our study indicated that the preseason $T_{\min }$ had a significant effect on the photosynthetic phenology of subtropical evergreen vegetation, providing new insights into how climate change affects the EGS. These results also provide a scientific basis for the development of phenology models for evergreen vegetation.

\section{Abbreviations}

SIF: Solar-induced Chlorophyll Fluorescence; EVI: Enhanced Vegetation Index; NIRv: Near-infrared Reflectance of Vegetation; EGS: The End of the Growing Season; SOS: The Start of the Growing Season; ECF: Evergreen Coniferous Forest; EBF: Evergreen Broadleaved Forest; DBF: Deciduous Broadleaved Forest; $T_{\text {max }}$ : Maximum Temperature; $T_{\min }$ : Minimum Temperature; GPP: Gross Primary Productivity; NDVI: Normalized Difference Vegetation Index; WPL: Webb-Pearman-Leuning

\section{Supplementary Information}

The online version contains supplementary material available at https://doi. org/10.1186/s40663-021-00309-9.

Additional file 1: Figure S1. The spatial patterns of the end of growing season (EGS) in subtropical vegetation in China from 2000 to 2018: NIRv dataset. a) derivative method and b) dynamic threshold method. Inset plots (the bottom-left of each figure) display the frequency distribution of EGS. Figure S2. Comparison of the end of growing season (EGS) retrieved from NIRv and flux data. Two ecological monitoring stations were listed, including Qianyanzhou station (QYZ) and Dinghushan station (DHS). Both methods were listed, including derivative and dynamic threshold methods. Figure S3. Linear trends of the end of growing season (EGS) across China's Subtropical biomes from 2000 to 2018. Five main vegetation types in study area were listed, including evergreen coniferous forest (ECF), evergreen broadleaved forest (EBF), deciduous broadleaved forest (DBF), shrub, and grassland. a) derivative and b) dynamic threshold method. A negative value indicates an advance, and a positive value indicates a delay. ${ }^{*}$ indicates statistically significant trends at the $90 \%(P<0.1)$ level, ${ }^{* *}$ indicates statistically significant trends at the $95 \%(P<0.05)$ level. Figure S4. The spatial patterns of the linear trend of the end of growing season (EGS) of subtropical vegetation in China from 2000 to 2018: NIRv dataset. a) derivative method and b) dynamic threshold method. Inset plots (the bottom-left of each figure) display the frequency distribution of change trend. The proportions of positive $(\mathrm{P})$ and negative $(\mathrm{N})$ (proportions of significant in parentheses) trends are provided. Figure S5. Linear trends of the end of growing season (EGS) across China's Subtropical biomes from 2000 to 2018: NIRv dataset. Five main vegetation types in study area were listed, including evergreen coniferous forest (ECF), evergreen broadleaved forest (EBF), deciduous broadleaved forest (DBF), shrub, and grassland. a) derivative and b) dynamic threshold method. A negative value indicates an advance, and a positive value indicates a delay. * indicates statistically significant trends at the $90 \%(P<0.1)$ level,
** indicates statistically significant trends at the $95 \%(P<0.05)$ level. Figure S6. Optimal preseason periods depicting correlations between the end of growing season (EGS) derived from SIF data and climatic factors: Precipitation (Pre), maximum temperature $\left(T_{\max }\right)$ and minimum temperature $\left(T_{\mathrm{min}}\right)$. Two methods (derivative and dynamic threshold methods) were listed. Figure S7. Sensitivity of end of growing season (EGS) to climatic factors in different vegetation types. Five main vegetation types in study area were listed, including evergreen coniferous forest (ECF), evergreen broadleaved forest (EBF), deciduous broadleaved forest $(\mathrm{DBF})$, shrub, and grassland. a) derivative and b) dynamic threshold method. 1 day.sd $\mathrm{d}^{-1}$ denoted that an increase of 1 standard deviation (sd) in the climatic factors delayed or advanced the EGS by 1 day. Figure $\mathbf{S 8 .}$ The seasonal cycles of SIF and flux tower GPP from 2003 to 2010. Table S1. The change rate and significance of three climate factors in different vegetation areas from 2000 to 2018, including precipitation (Pre), maximum temperature $\left(T_{\max }\right)$ and minimum temperature $\left(T_{\min }\right)$. Five main biomes in this study area were listed, such as evergreen coniferous forest (ECF), evergreen broadleaved forest (EBF), deciduous broadleaved forest (DBF), shrub, and grassland.

\section{Acknowledgements}

The authors would like to acknowledge the National Tibetan Plateau Data Center, National Aeronautics and Space Administration (NASA) and ChinaFLUX for providing the data. We thank the two anonymous reviewers for helping us improve the manuscript.

\section{Authors' contributions}

PR acquired the data, analyzed the data, and drafted the manuscript. PL analyzed the data and conceived and designed the study. PL, ZL, XZ, CP, JX, SW and XL revised the important intellectual content critically. The authors read and approved the final manuscript.

\section{Funding}

This study was financially supported by the National Natural Science Foundation of China (Grant No. 41901117), Natural Science Foundation of Hunan Province, China (Grant No. 2020JJ5362), the Outstanding Youth Project of Hu'nan Provincial Education Department (No. 18B001), and the Natural Sciences and Engineering Research Council of Canada (NSERC) Discover Grant.

\section{Availability of data and materials}

The GOSIF product is available from https://globalecology.unh.edu/data.html. The MODIS EVI product analysed during the current study is available in the NASA, https://ladsweb.modaps.eosdis.nasa.gov/search/. The meteorological data is available from https://data.tpdc.ac.cn/zh-hans/. The flux data is available in the national flux network of China, http://www.cern.ac.cn/ Oindex/index.asp. Other datasets used during the current study are available from the authors on reasonable request.

\section{Declarations}

Ethics approval and consent to participate

Not applicable.

\section{Consent for publication}

Not applicable.

\section{Competing interests}

The authors declare that they have no competing interests.

\section{Author details}

${ }^{1}$ College of Geographic Science, Hunan Normal University, Changsha 410081, China. ${ }^{2}$ Department of Biology Sciences, Institute of Environment Sciences, University of Quebec at Montreal, C.P. 8888, Succ. Centre-Ville, Montreal H3C 3P8, Canada. ${ }^{3}$ Earth Systems Research Center, Institute for the Study of Earth, Oceans, and Space, University of New Hampshire, Durham, NH 03824, USA. ${ }^{4}$ International Institute for Earth System Sciences, Nanjing University, Nanjing 210023, China. ${ }^{5}$ Jiangsu Provincial Key Laboratory of Geographic Information Technology, Key Laboratory for Land Satellite Remote Sensing Applications 
of Ministry of Natural Resources, School of Geography and Ocean Science, Nanjing University, Nanjing 210023, China.

\section{Received: 4 January 2021 Accepted: 27 April 2021 Published online: 19 May 2021}

\section{References}

Baker NR (2008) Chlorophyll fluorescence: a probe of photosynthesis in vivo. Annu Rev Plant Biol 59(1):89-113. https://doi.org/10.1146/annurev.arplant.59. 032607.092759

Balzarolo M, Vicca S, Nguy-Robertson AL, Bonal D, Elbers JA, Fu YH, Gruenwald T, Horemans JA, Papale D, Penuelas J, Suyker A, Veroustraete F (2016) Matching the phenology of net ecosystem exchange and vegetation indices estimated with MODIS and FLUXNET in-situ observations. Remote Sens Environ 174: 290-300. https://doi.org/10.1016/j.rse.2015.12.017

Bertani G, Wagner F, Anderson L, Aragão L (2017) Chlorophyll fluorescence data reveals climate-related photosynthesis seasonality in Amazonian forests. Remote Sens 9(12):1275. https://doi.org/10.3390/rs9121275

ChinaFLUX (2013) The flux data of the Dinghushan and Qianyanzhou research stations from 2003 to 2010. http://www.cern.ac.cn/0index/index.asp. Accessed 20 Jun 2020

Chuine I, Morin X, Bugmann H (2010) Warming, photoperiods, and tree phenology. Science 329(5989):277-278. https://doi.org/10.1126/science.329. 5989.277-e

Cleland E, Chuine I, Menzel A, Mooney H, Schwartz M (2007) Shifting plant phenology in response to global change. Trends Ecol Evol 22(7):357-365. https://doi.org/10.1016/j.tree.2007.04.003

Estiarte M, Penuelas J (2015) Alteration of the phenology of leaf senescence and fall in winter deciduous species by climate change: effects on nutrient proficiency. Glob Chang Biol 21(3):1005-1017. https://doi.org/10.1111/gcb.12804

Filippa G, Cremonese E, Migliavacca M, Galvagno M, Forkel M, Wingate L, Tomelleri E, Morra Di Cella U, Richardson AD (2016) Phenopix: a R package for image-based vegetation phenology. Agric For Meteorol 220:141-150. https://doi.org/10.1016/j.agrformet.2016.01.006

Flynn DFB, Wolkovich EM (2018) Temperature and photoperiod drive spring phenology across all species in a temperate forest community. New Phytol 219(4):1353-1362. https://doi.org/10.1111/nph.15232

Forkel M, Migliavacca M, Thonicke K, Reichstein M, Schaphoff S, Weber U (2015) Codominant water control on global interannual variability and trends in land surface phenology and greenness. Glob Chang Biol 21(9):3414-3435. https://doi.org/10.1111/gcb.12950

Frankenberg C, O'Dell C, Berry J, Guanter L, Joiner J, Köhler P, Pollock R, Taylor TE (2014) Prospects for chlorophyll fluorescence remote sensing from the orbiting carbon Observatory-2. Remote Sens Environ 147:1-12. https://doi. org/10.1016/j.rse.2014.02.007

Fu YH, Piao S, Zhao H, Jeong SJ, Wang X, Vitasse Y, Ciais P, Janssens IA (2014) Unexpected role of winter precipitation in determining heat requirement for spring vegetation green-up at northern middle and high latitudes. Glob Chang Biol 20(12):3743-3755. https://doi.org/10.1111/gcb.12610

Fu YH, Zhao H, Piao S, Peaucelle M, Peng S, Zhou G, Ciais P, Huang M, Menzel A, Peñuelas J, Song Y, Vitasse Y, Zeng Z, Janssens IA (2015) Declining global warming effects on the phenology of spring leaf unfolding. Nature 526(7571):104-107. https://doi.org/10.1038/nature15402

Gallinat AS, Primack RB, Wagner DL (2015) Autumn, the neglected season in climate change research. Trends Ecol Evol 30(3):169-176. https://doi.org/10.1 016/j.tree.2015.01.004

Garonna I, de Jong R, de Wit AJ, Mucher CA, Schmid B, Schaepman ME (2014) Strong contribution of autumn phenology to changes in satellite-derived growing season length estimates across Europe (1982-2011). Glob Chang Biol 20(11):3457-3470. https://doi.org/10.1111/gcb.12625

Ge Q, Wang H, Rutishauser T, Dai J (2015) Phenological response to climate change in China: a meta-analysis. Glob Chang Biol 21(1):265-274. https://doi. org/10.1111/gcb.12648

Guanter L, Zhang Y, Jung M, Joiner J, Voigt M, Berry JA, Frankenberg C, Huete AR, Zarco-Tejada P, Lee JE, Moran MS, Ponce-Campos G, Beer C, Camps-Valls G, Buchmann N, Gianelle D, Klumpp K, Cescatti A, Baker JM, Griffis TJ (2014) Global and time-resolved monitoring of crop photosynthesis with chlorophyll fluorescence. Proc Natl Acad Sci U S A 111(14):E1327-E1333. https://doi.org/10.1073/pnas.1320008111
He J, Yang K, Tang W, Lu H, Qin J, Chen Y, Li X (2020) The first high-resolution meteorological forcing dataset for land process studies over China. Sci Data 7(1):25. https://doi.org/10.1038/s41597-020-0369-y

Helmut L (1974) Phenology and seasonality modeling. Springer-Verlag Berlin Heidelberg, New York

Huete A, Didan K, Miura T, Rodriguez EP, Gao X, Ferreira LG (2002) Overview of the radiometric and biophysical performance of the MODIS vegetation indices. Remote Sens Environ 83(1-2):195-213. https://doi.org/10.1016/ S0034-4257(02)00096-2

Jeong SJ, Schimel D, Frankenberg C, Drewry DT, Fisher JB, Verma M, Berry JA, Lee JE, Joiner J (2017) Application of satellite solar-induced chlorophyll fluorescence to understanding large-scale variations in vegetation phenology and function over northern high latitude forests. Remote Sens Environ 190: 178-187. https://doi.org/10.1016/j.rse.2016.11.021

Jiang Z, Huete A, Didan K, Miura T (2008) Development of a two-band enhanced vegetation index without a blue band. Remote Sens Environ 112(10):38333845. https://doi.org/10.1016/j.rse.2008.06.006

Joiner J, Yoshida Y, Vasilkov AP, Schaefer K, Jung M, Guanter L, Zhang Y, Garrity S, Middleton EM, Huemmrich KF, Gu L, Marchesini LB (2014) The seasonal cycle of satellite chlorophyll fluorescence observations and its relationship to vegetation phenology and ecosystem atmosphere carbon exchange. Remote Sens Environ 152:375-391. https://doi.org/10.1016/j.rse.2014.06.022

Karkauskaite P, Tagesson T, Fensholt R (2017) Evaluation of the plant phenology index (PPI), NDVI and EVI for start-of-season trend analysis of the northern hemisphere boreal zone. Remote Sens 9(5):485. https://doi.org/10.3390/ rs9050485

Köhler P, Guanter L, Kobayashi H, Walther S, Yang W (2018) Assessing the potential of sun-induced fluorescence and the canopy scattering coefficient to track large-scale vegetation dynamics in Amazon forests. Remote Sens Environ 204:769-785. https://doi.org/10.1016/j.rse.2017.09.025

Li X, Xiao J (2019a) A global, 0.05-degree product of solar-induced chlorophyll fluorescence derived from OCO-2, MODIS, and reanalysis data. Remote Sens 11:517

Li X, Xiao J (2019b) Mapping photosynthesis solely from solar-induced chlorophyll fluorescence: a global, fine-resolution dataset of gross primary production derived from OCO-2. Remote Sens 11(21):2563. https://doi.org/1 $0.3390 / \mathrm{rs} 11212563$

Li X, Xiao J (2020) Global climatic controls on interannual variability of ecosystem productivity: similarities and differences inferred from solar-induced chlorophyll fluorescence and enhanced vegetation index. Agric For Meteorol https://doi.org/10.1016/j.agrformet.2020.108018. Accessed 20 Jun 2020 288289:108018

Liu Q, Fu YH, Zeng Z, Huang M, Li X, Piao S (2016) Temperature, precipitation, and insolation effects on autumn vegetation phenology in temperate China. Glob Chang Biol 22(2):644-655. https://doi.org/10.1111/gcb.13081

Liu X, Zhou L, Shi H, Wang S, Chi Y (2018) Phenological characteristics of temperate coniferous and broad-leaved mixed forests based on multiple remote sensing vegetation indices, chlorophyll fluorescence and $\mathrm{CO}_{2}$ flux data. Acta Ecol Sin 38(10):3482-3494

Menzel A, Sparks TH, Estrella N, Koch E, Aasa A, Ahas R, Alm-Kubler K, Bissolli P, Braslavska O, Briede A, Chmielewski FM, Crepinsek Z, Curnel Y, Dahl A, Defila C, Donnelly A, Filella Y, Jatcza K, Mage F, Mestre A, Nordli O, Penuelas J, Pirinen P, Remisova V, Scheifinger H, Striz M, Susnik A, Van Vliet AJH, Wielgolaski FE, Zach S, Zust A (2006) European phenological response to climate change matches the warming pattern. Glob Chang Biol 12(10):19691976. https://doi.org/10.1111/j.1365-2486.2006.01193.x

Miura T, Huete AR, Yoshioka H, Holben BN (2001) An error and sensitivity analysis of atmospheric resistant vegetation indices derived from dark target-based atmospheric correction. Remote Sens Environ 78(3):284-298. https://doi.org/1 0.1016/S0034-4257(01)00223-1

NASA (2015) MOD13C1. https://ladsweb.modaps.eosdis.nasa.gov/search/.

National Tibetan Plateau Data Center (2019) China meteorological forcing dataset (1979-2018). https://data.tpdc.ac.cn/zh-hans/. Accessed 10 Oct 2019

Penuelas J, Filella I, Rutishauser T (2009) Phenology feedbacks on climate change. Science 324:910-913

Piao S, Ciais P, Friedlingstein P, Peylin P, Reichstein M, Luyssaert S, Margolis H, Fang J, Barr A, Chen A, Grelle A, Hollinger DY, Laurila T, Lindroth A, Richardson AD, Vesala $T$ (2008) Net carbon dioxide losses of northern ecosystems in response to autumn warming. Nature 451(7174):49-52. https://doi.org/10.1038/nature06444 
Piao S, Liu Q, Chen A, Janssens IA, Fu Y, Dai J (2019) Plant phenology and global climate change: current progresses and challenges. Glob Chang Biol 25(6): 1922-1940. https://doi.org/10.1111/gcb.14619

Qiu R, Han G, Ma X, Xu H, Shi T, Zhang M (2020) A comparison of OCO-2 SIF, MODIS GPP, and GOSIF data from gross primary production (GPP) estimation and seasonal cycles in North America. Remote Sens 12(2):258. https://doi. org/10.3390/rs12020258

Quetin GR, Swann ALS (2017) Empirically derived sensitivity of vegetation to climate across global gradients of temperature and precipitation. J Clim 30(15):5835-5849. https://doi.org/10.1175/JCLI-D-16-0829.1

Richardson AD, Keenan TF, Migliavacca M, Ryu Y, Sonnentag O, Toomey M (2013) Climate change, phenology, and phenological control of vegetation feedbacks to the climate system. Agric For Meteorol 169:156-173. https://doi. org/10.1016/j.agrformet.2012.09.012

Rossi S, Burgess P, Jespersen D, Huang B (2017) Heat-induced leaf senescence associated with chlorophyll metabolism in bentgrass lines differing in heat tolerance. Crop Sci 57:S169-S178

Suepa T, Qi J, Lawawirojwong S, Messina JP (2016) Understanding spatiotemporal variation of vegetation phenology and rainfall seasonality in the monsoon Southeast Asia. Environ Res 147:621-629. https://doi.org/10.1016/j. envres.2016.02.005

Sun Y, Frankenberg C, Wood JD, Schimel DS, Jung M, Guanter L, Drewry DT, Verma M, Porcar-Castell A, Griffis TJ, Gu L, Magney TS, Köhler P, Evans B, Yuen K (2017) OCO-2 advances photosynthesis observation from space via solarinduced chlorophyll fluorescence. Science 358:m5747

Vrieling A, Meroni M, Darvishzadeh R, Skidmore AK, Wang T, Zurita-Milla R, Oosterbeek K, O'Connor B, Paganini M (2018) Vegetation phenology from Sentinel-2 and field cameras for a Dutch barrier island. Remote Sens Environ 215:517-529. https://doi.org/10.1016/j.rse.2018.03.014

Walther S, Voigt M, Thum T, Gonsamo A, Zhang Y, Köhler P, Jung M, Varlagin A, Guanter L (2016) Satellite chlorophyll fluorescence measurements reveal large-scale decoupling of photosynthesis and greenness dynamics in boreal evergreen forests. Glob Chang Biol 22(9):2979-2996. https://doi.org/10.1111/ gcb. 13200

Wang S, Zhang Y, Ju W, Qiu B, Zhang Z (2021) Tracking the seasonal and interannual variations of global gross primary production during last four decades using satellite near-infrared reflectance data. Sci Total Environ 755: 142569. https://doi.org/10.1016/j.scitotenv.2020.142569

Wang X, Xiao J, Li X, Cheng G, Ma M, Zhu G, Altaf AM, Andrew BT, Jassal RS (2019a) No trends in spring and autumn phenology during the global warming hiatus. Nat Commun 10(1):2389. https://doi.org/10.1038/s41467-01 9-10235-8

Wang Y, Luo Y, Shafeeque M (2019b) Interpretation of vegetation phenology changes using daytime and night-time temperatures across the Yellow River Basin. China Sci Total Environ 693:133553. https://doi.org/10.1016/j.scitotenv.2 019.07.359

Wen Z, Wu S, Chen J, Lu M (2017) NDVI indicated long-term interannual changes in vegetation activities and their responses to climatic and anthropogenic factors in the three gorges reservoir region, China. Sci Total Environ 574:947959. https://doi.org/10.1016/j.scitotenv.2016.09.049

White MA, Beurs KMD, Didan K, Inouye DW, Richardson AD, Jensen OP (2009) Intercomparison, interpretation, and assessment of spring phenology in North America estimated from remote sensing for 1982-2006. Glob Chang Biol 15(10):2335-2359. https://doi.org/10.1111/j.1365-2486.2009.01910.x

Wong CYS, D'Odorico P, Bhathena Y, Arain MA, Ensminger I (2019) Carotenoid based vegetation indices for accurate monitoring of the phenology of photosynthesis at the leaf-scale in deciduous and evergreen trees. Remote Sens Environ 233:111407

Wu C, Wang X, Wang H, Ciais P, Peñuelas J, Myneni RB, Desai AR, Gough CM, Gonsamo A, Black AT, Jassal RS, Ju W, Yuan W, Fu Y, Shen M, Li S, Liu R, Chen JM, Ge Q (2018) Contrasting responses of autumn-leaf senescence to daytime and night-time warming. Nat Clim Chang 8(12):1092-1096. https:// doi.org/10.1038/s41558-018-0346-z

Xiao (2019) GOSIF-Global, OCO-2 based SIF product. http://globalecology.unh. edu/data/GOSIF.html. Accessed 10 Sep 2019

Xiao X, Zhang J, Yan H, Wu W, Biradar C (2009) Land surface phenology: convergence of satellite and CO2 eddy flux observation. In: Noormets A (ed) Phenology of ecosystem processes. Springer, New York, pp 247-270. https:// doi.org/10.1007/978-1-4419-0026-5_11

Xu W, Wu B, Yan C, Huang H (2005) China land cover 2000 using SPOT VGT S10 data. J Remote Sens 9:204-214
Xu X, Riley WJ, Koven CD, Jia G (2018) Observed and simulated sensitivities of spring Greenup to preseason climate in northern temperate and boreal regions. J Geophys Res-Biogeo 123(1):60-78. https://doi.org/10.1002/201 7JG004117

Yang K, He J, Tang WJ, Qin J, Cheng CCK (2010) On downward shortwave and longwave radiations over high altitude regions: observation and modeling in the Tibetan plateau. Agric For Meteorol 150(1):38-46. https://doi.org/10.1016/ j.agrformet.2009.08.004

Yang X, Tang J, Mustard JF, Lee J, Rossini M, Joiner J, Munger JW, Kornfeld A, Richardson AD (2015) Solar-induced chlorophyll fluorescence that correlates with canopy photosynthesis on diurnal and seasonal scales in a temperate deciduous forest. Geophys Res Lett 42(8):2977-2987. https://doi.org/10.1 002/2015GL063201

Yang Z, Shen M, Jia S, Guo L, Yang W, Wang C, Chen X, Chen J (2017) Asymmetric responses of the end of growing season to daily maximum and minimum temperatures on the Tibetan plateau: autumn phenology on Tibetan plateau. J Geophys Res-Atmos 122(24):13278-13287. https://doi.org/1 0.1002/2017JD027318

Yin G, Verger A, Filella I, Descals A, Peñuelas J (2020) Divergent estimates of forest photosynthetic phenology using structural and physiological vegetation indices. Geophys Res Lett 47(18):1. https://doi.org/10.1029/202 OGL089167

Yoshida Y, Joiner J, Tucker C, Berry J, Lee JE, Walker G, Reichle R, Koster R, Lyapustin A, Wang Y (2015) The 2010 Russian drought impact on satellite measurements of solar-induced chlorophyll fluorescence: insights from modeling and comparisons with parameters derived from satellite reflectances. Remote Sens Environ 166:163-177. https://doi.org/10.1016/j.rse.2 015.06 .008

Yuan H, Wu C, Lu L, Wang X (2018) A new algorithm predicting the end of growth at five evergreen conifer forests based on nighttime temperature and the enhanced vegetation index. ISPRS J Photogramm 144:390-399. https://doi.org/10.1016/j.isprs.jprs.2018.08.013

Zhang X, Friedl MA, Schaaf CB, Strahler AH, Hodges JCF, Gao F, Reed BC, Huete A (2003) Monitoring vegetation phenology using MODIS. Remote Sens Environ 84(3):471-475. https://doi.org/10.1016/S0034-4257(02)00135-9

Zhang Y, Peng C, Li W, Tian L, Zhu Q, Chen H (2016) Multiple afforestation programs accelerate the greenness in the 'three north' region of China from 1982 to 2013 Ecol Indic 61:404-412. https://doi.org/10.1016/j.ecolind.2015.09.041

Zhou Q, Luo Y, Zhou X, Cai M, Zhao C (2018) Response of vegetation to water balance conditions at different time scales across the karst area of southwestern China - a remote sensing approach. Sci Total Environ 645:460470. https://doi.org/10.1016/j.scitotenv.2018.07.148

Zuromski LM, Bowling DR, Köhler P, Frankenberg C, Goulden ML, Blanken PD, Lin JC (2018) Solar-induced fluorescence detects interannual variation in gross primary production of coniferous forests in the western United States. Geophys Res Lett 45(14):7184-7193. https://doi.org/10.1029/2018GL077906

\section{Submit your manuscript to a SpringerOpen ${ }^{\circ}$ journal and benefit from:}

- Convenient online submission

- Rigorous peer review

- Open access: articles freely available online

- High visibility within the field

- Retaining the copyright to your article

Submit your next manuscript at $>$ springeropen.com 